\title{
EPENDIMOMAS
}

\section{ACHADOS CLÍNICOS, EPIDEMIOLÓGICOS E ANATOMOPATOLÓGICOS DE 22 CASOS}

\author{
LUIZ FERNANDO BLEGGI TORRES*, JORGE SERGIO REIS FILHO**, MÁRIO R. MONTEMÓR NETTO**, \\ LINEI A. B. DELLÉ ${ }^{* * *}$, BEATRIZ GARCIA SLUMINSKY***, FÁBIO ANTONNIO TIRONI***, \\ AFONSO ANTONIUK ${ }^{* * * *}$, RICARDO RAMINA ${ }^{* * * * *}$
}

\begin{abstract}
RESUMO - Ependimomas são neoplasias compostas por células ependimárias neoplásicas, manifestando-se predominantemente em crianças e adultos jovens. Relatamos os achados clínicos, epidemiológicos e anatomopatológicos de 22 casos de ependimomas. Dos 22 casos analisados, 14 ocorreram em pacientes do sexo masculino e 8 em pacientes femininos. As idades variaram de 1 a 58 anos, com média de 24,63 anos. Quanto à localização, 10 casos acometeram medula, 7 ocorreram em hemisférios cerebrais, 2 intraventriculares e 1 no tronco cerebral. Os sinais e sintomas observados incluiram redução da força muscular (59,1\% dos pacientes), alterações da marcha (36,3\%), alterações da sensibilidade(36,3\%), hiperreflexia e sindrome de hipertensão endocraniana, com período de evolução variando de 15 dias a 8 anos, com média de 17,58 meses. Sete pacientes foram submetidos a ressecção cirúrgica total , 7 a exérese parcial, 4 a exérese parcial associada a radioterapia adjuvante, 3 a ressecção parcial seguida de quimioterapia e 1 a tumorectomia total associada a radioterapia. Evidenciou-se taxa de recidiva tumoral total de $18,2 \%$. Estes achados aproximam-se dos encontrados na literatura internacional, corroborando para a compreensão do comportamento biológico deste tumor.
\end{abstract}

PALAVRAS-CHAVE: ependimomas, neoplasias do sistema nervoso central, tumores cerebrais.

\section{Ependymonas: clinical, epidemiological and pathological findings of 22 cases}

ABSTRACT - Ependymomas are composed of neoplastic ependymal cells, affecting mainly children and young adults. We report the clinical and pathological findings of 22 cases of ependymomas. Fourteen patients were males and 8 were females. The ages ranged between 1 and 58 years, with a mean of 24.63 years. The symptoms reflected the growth and topography of the tumours; muscle weakness (59.1\%), gait disorders (36.3\%), sensitive disorders (36.3\%), hyperreflexia and intracranial hypertension syndrome were the most frequent symptoms. Ten tumours affected the medulla, 7 the cerebral hemispheres, 2 the cerebral ventricles and 1 brain stem. Seven patients were submitted total resection of the tumor, from which one received adjuvant radiotherapy. 15 other patients were submitted to partial resection; from which 4 received adjuvant radiotherapy, 3 adjuvant chemotherapy and 1 chemotherapy and radiotherapy. The recurrence rate was $18.2 \%$. These results are similar with the literature and may contribute to further understanding the biological behavior of these tumours.

KEY WORDS: ependymomas, central nervous system tumours, brain tumours.

Os ependimomas se originam da camada ependimária que recobre os ventrículos cerebrais e o canal central da medula espinhal, manifestando-se em crianças e adultos jovens, com características morfológicas e comportamento biológico extremamente variáveis ${ }^{1-4}$. Relatamos os achados

Estudo realizado na Seção de Microscopia Eletrônica e Neuropatologia de Serviço de Anatomia Patológica (SAP), Hospital de Clínicas (HC) da Universiade Federal do Paraná (UFPR), Curitiba, PR: *PhD em Neuropatologia (Londres); Chefe do SAP - HC - UFPR. **Médico Residente SAP - HC - UFPR; ***Estagiário da Seção de Microscopia Eletrônica e Neuropatologia SAP - HC- UFPR. ****Professor Titular da Disciplina de Neurocirurgia - UFPR; *****Médico Neurocirurgião do Hospital das Nações - Curitiba.

Dr. Luiz Fernando Bleggi Torres - Serviço de Anatomia Patológica, Hospital de Clínicas - Rua General Carneiro 181 - 80060-900 Curitiba PR - Brasil. Fax 041264 1304. E-mail: bleggi@hc.ufpr.br e lftorres@uol.com.br 
anatomopatológicos e clínico-prognósticos de 22 casos de ependimomas diagnosticados em pacientes da Cidade de Curitiba no período compreendido entre 1990 e 1997, realizando correlação entre o tratamento e o prognóstico dos portadores desta neoplasia. Até o presente momento, este é um dos escassos estudos clínico-patológico na literatura latino americana indexada no MEDLINE e LILACS.

\section{MÉTODO}

Este estudo deriva de linha de pesquisa denominada "Banco de Patologia Tumoral do Sistema Nervoso Central da População da Cidade de Curitiba", que tem como objetivo tabular todos os dados referentes aos tumores do sistema nervoso central (SNC) que acometem a população dessa cidade e sua região metropolitana. A pesquisa tem o intuito de analisar epidemiologicamente os principais tumores do SNC. Para tanto, foram pesquisados os livros de registros ou arquivos de biópsias do período de 1990 a 1997 dos Serviços de Anatomia Patológica dos principais hospitais da Cidade de Curitiba que são responsáveis por mais de $95 \%$ da rotina neurocirúrgica do município. Do total de biópsias de diversos órgãos e tecidos realizadas neste período, foram compiladas as de SNC, pesquisando-se o sexo, idade, localização tumoral e diagnóstico histológico. Deste total, foram separados os ependimomas avaliando-se as variáveis sexo, idade e localização tumoral. Os dados clínicos dos pacientes, como história clínica, tempo de evolução dos sintomas, exame físico, tratamento e evolução foram obtidos a partir dos prontuários médicos. Todas as biópsias foram preparadas conforme técnicas histológicas convencionais ${ }^{5}$, sendo utilizados os critérios da Classficação da Organização Mundial de Saúde (OMS) ${ }^{3}$ para o diagnóstico dos ependimomas, sendo subdividos em ependimomas (grau II da OMS) e ependimomas anaplásicos (grau III da OMS).

\section{RESULTADOS}

Das 3318 biópsias realizadas, 2427 (73,14\%) corresponderam a neoplasias primárias do SNC e, dentre estas, 74 (3,04\%) tiveram diagnóstico histológico de ependimomas. Destes, 52 não apresentaram dados clínicos prognósticos suficientes para a inclusão no estudo. Dos 22 pacientes analisados, 14 tiveram diagnóstico histológico de ependimomas e 8 foram diagnosticados como ependimomas anaplásicos. Quatorze casos ocorreram em pacientes do sexo masculino e oito em pacientes femininos (Figs 1A e 1B). As idades variaram de 1 a 58 anos, com média de 35,93 anos nos pacientes portadores de ependimomas e de 4,87 nos portadores de ependimomas anaplásicos (Fig 2). Quanto à localização, 10 casos acometeram a medula espinhal, sete ocorreram em hemisférios cerebrais, dois intraventriculares e um em tronco cerebral (Fig 3). Os sinais e sintomas observados incluiram redução da força muscular (59,1\% dos pacientes), alterações da marcha (36,3\% dos pacientes), alterações da sensibilidade (36,3\%), hiperreflexia e síndrome de hipertensão endocraniana (Fig 4), com período de evolução variando de 1 a 96 meses para os pacientes com ependimomas (média 21,42 meses) e 15 dias a 12 meses para os pacientes com ependimomas anaplásicos (média 4,12 meses). Sete pacientes foram submetidos a ressecção cirúrgica total , 7 a exérese parcial, 4 a exérese parcial associada a radioterapia adjuvante, 3 a ressecção parcial seguida de quimioterapia e 1 a tumorectomia total associada a radioterapia. Evidenciou-se recidiva tumoral em 2 pacientes com diagnóstico de ependimoma (14,28\%), sendo ambos submetidos apenas a tumorectomia parcial, com período médio de 24,5 meses entre o tratamento e a recidiva; entre os pacientes portadores de ependimomas anaplásicos, observou-se taxa de $25 \% \quad(n=2 / 8)$ de recidiva local com período médio

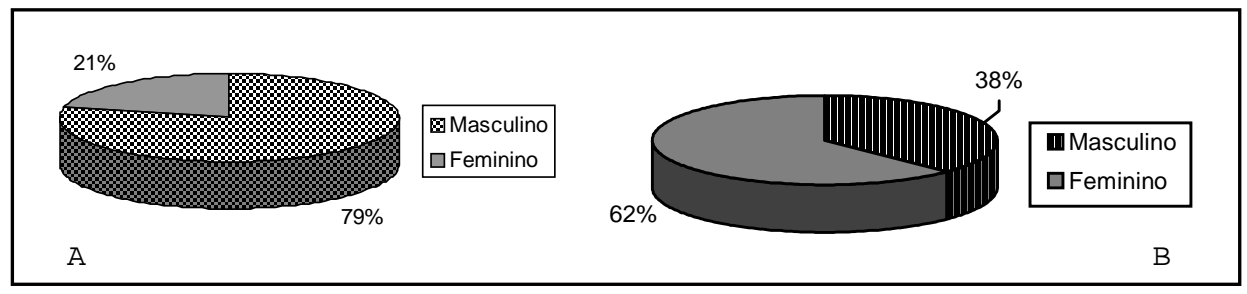

Fig 1A. Distribuição quanto ao sexo dos pacientes com ependimomas grau II OMS.

Fig 1B. Distribuição quanto ao sexo dos pacientes portadores de ependimomas anaplásicos. 


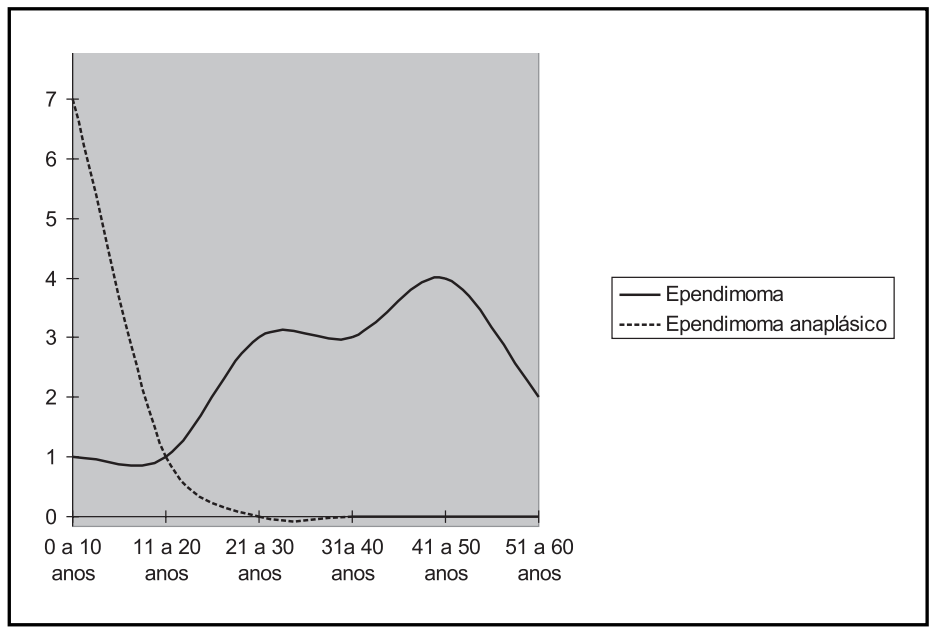

Fig 2. Distribuição etária dos pacientes portadores de ependimomas.

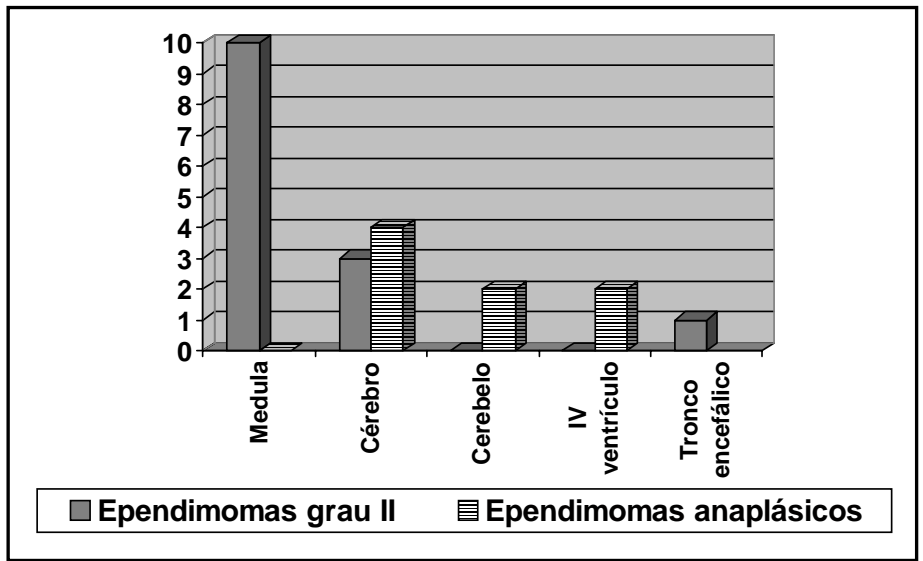

Fig 3. Localização dos tumores nos pacientes portadores de ependimomas.

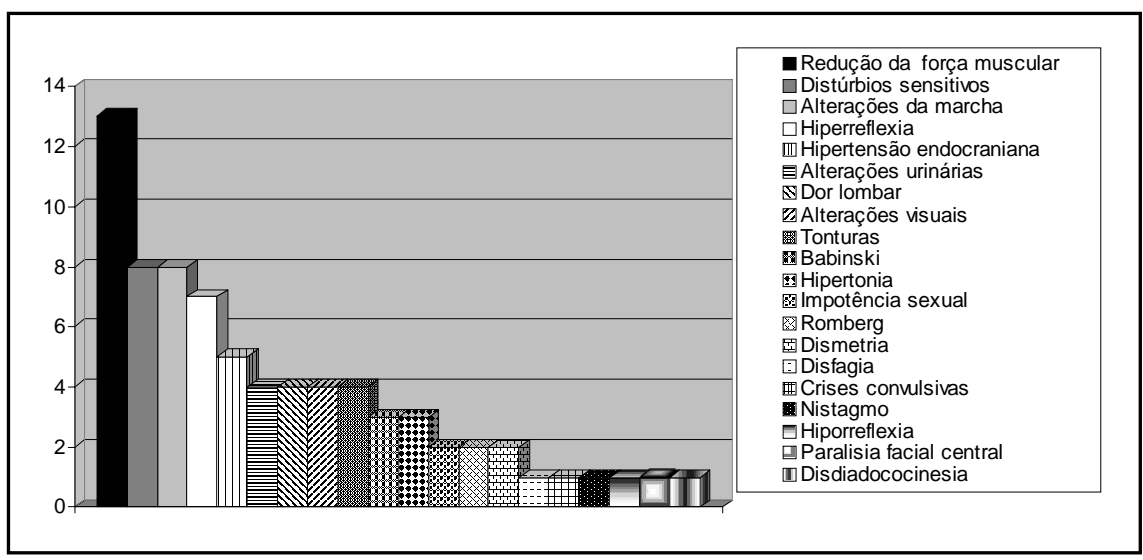

Fig 4. Sintomatologia apresentada pelos pacientes portadores de ependimomas. 


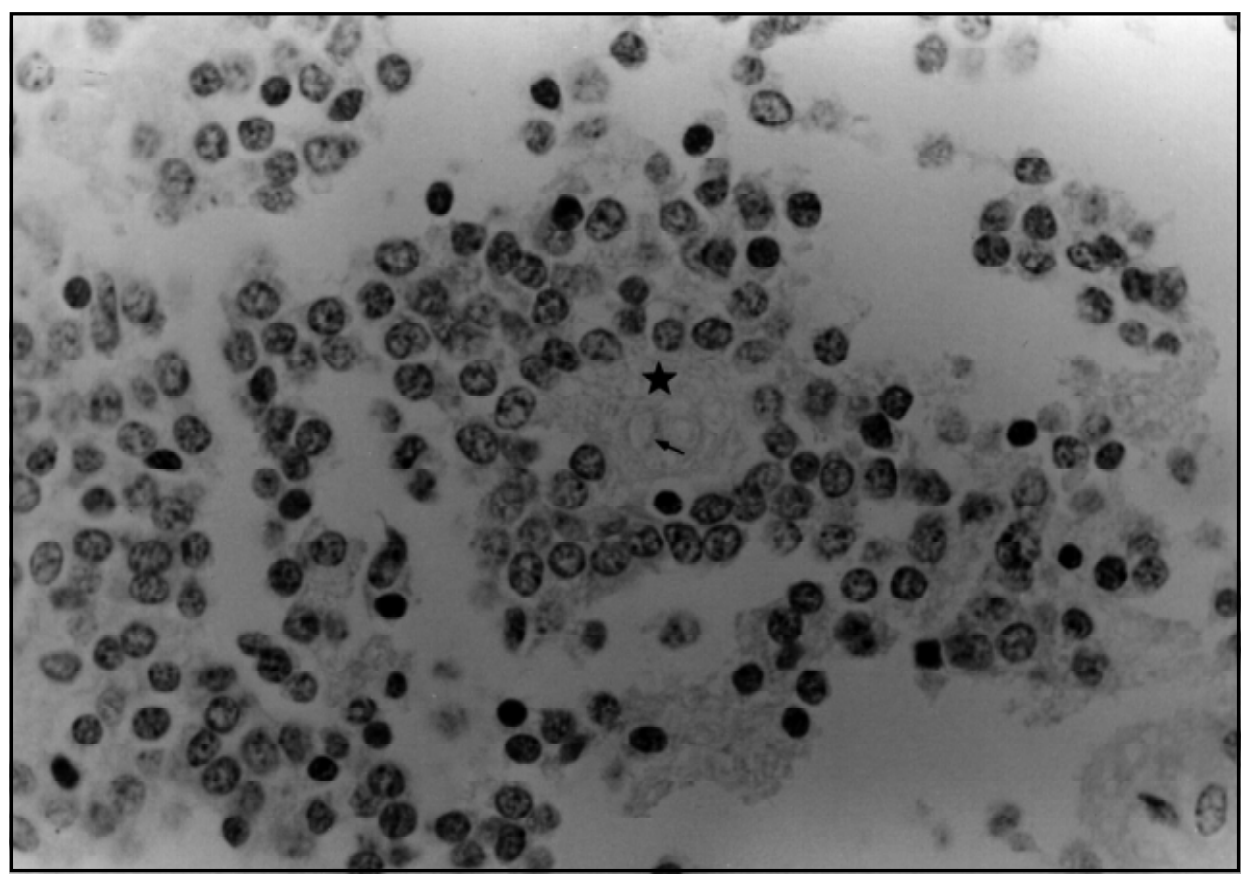

Fig 5. Corte histológico de ependimoma composto por células uniformes, cromatina delicada, com arranjo formando roseta verdadeira (*) com luz central seta). HE x 400.

de 10,5 meses, sendo ambos os pacientes submetidos a ressecção parcial associada em um dos casos a radioterapia e no outro, a quimioterapia (Tabela 1).

\section{DISCUSSÃO}

Os ependimomas correspondem a cerca de 3-9\% de todos os tumores neuroepiteliais sendo os gliomas mais frequentes na medula espinhal ${ }^{2,6,7}$. Do total de ependimomas até $1 / 4$ podem ser anaplásicos ou malignos ${ }^{4,8}$. Em nossa casuística, os ependimomas corresponderam a 3,04\% das neoplasias neuroepi-

Tabela 1. Avaliação da recidiva tumoral nos pacientes portadores de ependimomas.

\begin{tabular}{lllcc}
\hline Diagnóstico & Tratamento & Recidiva & $\begin{array}{c}\text { Período médio entre o tratamento } \\
\text { e a recidiva tumoral (meses) }\end{array}$ \\
\hline Ependimomas & RT & 7 & $0 / 7$ & 0 \\
& RP & 6 & $2 / 6$ & 24,5 \\
& RT+RTx & 1 & $0 / 1$ & 0 \\
Ependimomas anaplásicos & RP & 1 & $0 / 1$ & 0 \\
& RP+RTx & 4 & $1 / 4$ & 19 \\
& RP+QT & 3 & $1 / 3$ & 2 \\
\hline
\end{tabular}

RT, ressecção total; RP, ressecção parcial; RTx, radioterapia; QT, quimioterapia. 
teliais, sendo que $17,56 \%$ foram anaplásicos. Ocorrem em todas as faixas etárias porém com distribuição bimodal, com um pico nas primeiras duas décadas e outro entre 30 e $40 \operatorname{anos}^{2,6,9,10}$. Em nossa casuística, os ependimomas anaplásicos distribuíram-se todos na primeira década de vida, com relação mulheres e homens de 1,63:1; os ependimomas grau II apresentaram dupla moda de incidência, apresentando relação homens:mulheres de 4:1.

Na apresentação clínica registram-se vômitos, cefaléia, hidrocefalia secundária, ataxia, distúrbios visuais, confusão e paresia ${ }^{1,2,4,6,11}$. Nas lesões supratentorias, evidenciam-se déficits neurológicos focais, crises convulsivas e sinais de hipertensão endocraniana ${ }^{1,2,4,6,11}$. O tempo de evolução da sintomatologia é de cerca de 3 meses $^{1,2,4,6,11}$, sendo mais prolongado nos adultos ${ }^{1}$. Em nossa casuística, o tempo de evolução dos sintomas dos pacientes com ependimomas variou de 1 a 96 meses, com média de 21,43 meses; já os pacientes com ependimomas anaplásicos apresentaram evolução mais rápida.

Ependimomas são neoplasias de celularidade moderada, com morfologia nuclear monótona $^{1,2,4,6,8,11,12}$. Os principais achados são as rosetas ependimárias, representadas por células colunares dispostas em torno de um canal central, e as pseudo-rosetas perivasculares, constituídas de células neoplásicas circunjacentes aos vasos ${ }^{1,2,4,6,8,11,12}$. Degeneração mixóide, calcificação, necrose e focos de hemorragia podem ser observados ${ }^{1,2,4,6,8,11,12}$. Nas formas anaplásicas há aumento da celularidade, mitoses, proliferação vascular e por vezes focos de necrose ${ }^{8}$ (Fig 5). A análise imunohistoquímica evidencia reatividade focal para GFAP, havendo reação proeminente nas pseudo$\operatorname{rosetas}^{13,14}$. Tipicamente, são positivos para proteína $S 100^{13,14}$. O antígeno epitelial de membrana pode ser positivo na superfície luminal das rosetas ependimárias ${ }^{13,14}$.

Há possível associação da transformação neoplásica das células ependimárias com infecção pelo vírus SV40, o que foi demonstrado pela identificação de fragmentos de DNA viral nas células neoplásicas, bem como pela detecção imuno-histoquímica do antígeno $\mathrm{T}$ grande ${ }^{15}$. Há descrições esporádicas da associação de ependimomas com facomatoses, síndrome endócrina múltipla tipo $1^{16}$, síndrome da mutação de TP53 em células germinativas ${ }^{17} \mathrm{e}$ síndrome de $\operatorname{Turcot}^{18}$. Uma possível mutação no gene NF2 foi aventada ${ }^{19}$, contudo sua comprovação ainda não foi realizada em uma população estatisticamente significativa. Especula-se uma possível mutação no braço curto do cromossoma $17^{20}$, bem como no gene supressor do gene NF2 no gene 22q1219,21, Não houve qualquer evidência de possíveis alterações de receptores de membrana, tais como EGFR, CDKN2A, CDKN2B, CDK4 e CCND120.

As crianças apresentam prognóstico pior quando comparadas aos adultos, sendo ele especialmente reservado nos casos abaixo de 1 ano de idade ${ }^{1,2,4,6,9}$. As lesões supra e infratentoriais apresentam curso clínico pior quando comparadas às lesões de medula espinhal e cauda equina ${ }^{1,2,4,6,9,11}$. Com relação à graduação histológica, a sobrevida livre de doença se mostrou menor nos casos de ependimoma anaplásico, os quais têm tendência de disseminação pelo líquor ${ }^{1,2,4,6,8,9,11}$. Em nossa casuística, houve 5 casos de recidiva tumoral, proprocionalmente maior nos ependimomas anaplásicos.

\section{REFERÊNCIAS}

1. Duncan JA, Hoffman HJ. Intracranial ependymomas. In Kaye AH, Lows ERJ. Brain tumours. Edinburg: Churchill Livingstone, 1995:493-504.

2. Fokes EC Jr, Earle KM. Ependymomas: clinical and pathological aspects. J Neurosurg, 1969;30:585-594.

3. Kleihues P, Burger PC, Scheithauer BW. The New World Health Organization Classification of brain tumours. Brain Pathol, 1993;3:255-268.

4. Schiff D, Wen PY. Uncommon brain tumors. Neurol Clin, 1995;13:953-974.

5. Bancroft JD, Stevens A. Theory and practice of histological techniques. 2Ed. New York: Churchill Livingstone, 1982.

6. Kricheff II, Becker M, Schenk AS, Taveras JM. Intracranial ependymomas: factors influencing ependymoma prognosis. J Neurosurg, 1964;21:7-14.

7. Morantz RA, Keps JJ, Batnitzk S, Masterson BJ. Extraspinal ependymomas: report of three cases. J Neurosurg, 1979;51:383-391.

8. Schiffer D, Chio A, Cravioto H, et al.. Ependymoma: internal correlations among pathological signs: the anaplastic variant. Neurosurgery, 1991;29:206-210.

9. Kudo H, Oi S, Tamaki N, Nishida Y, Matsumoto S. Ependymoma diagnosed in the first year of life in Japan in collaboration with the National Society for Pediatric Neurosurgery. Child Nerv Syst, 1990;6:375-378. 
10. Yates AJ, Becker LE, Sachs LA. Brain tumors in childhood. Childs Brain, 1979;5:31-39.

11. Pierkahn A, Irsch JF, Houx FX, Renier D, Sainte Rose C. Intracranial ependymomas in childhood: survival and functional results of 47 cases. Child Brain, 1983;10:145-156.

12. Schiffer D, Chio A, Giordana MT, et al.. Histologic prognostic factors in ependymoma. Child Nerv Syst, 1991;7:177-182.

13. Kimura T, Budka H, Soler Federspiel S. A immunocytochemical comparison of the glia associated proteins glial fibrillary acidic protein (GFAP) and S100 protein (S100P) in human brain tumours. Clin Neuropathol, 1986;5:21-27.

14. Mannoji H, Becker LE. Ependymal and choroid plexus tumours: cytokeratin and GFAP protein expression. Cancer, 1988;61:1377-1385.

15. Lednicky JA, Garcea RL, Bergsagel DJ, Butel JS. Natural simian virus 40 strains are present in human chroid plexus and ependymoma tumors. Virology, 1995;212:710-717.

16. Kato H, Uchimura I, Morohoshi M, et al.. Multiple endocrine neoplasia type 1 associated with spinal ependymoma. Intern Med, 1996;35:285-289.

17. Metzger AK, Sheffield VC, Duyk G, Daneshvar L, Edwards MS, Cogen PH. Identification of a germline mutation of p53 gene in a patient with na intracranial ependymoma. Proc Natl Acad Sci USA, 1991;88:7825-7829.

18. Torres CF, Korones DN, Pilcher W. Multiple ependymomas in a patient with Turcot's syndrome. Med Pediatr Oncol, 1997;28:59-61.

19. Birch BD, Johnson JP, Parsa A, et al.. Frequent type 2 neurofibromatosis gene transcript mutations in sporadic intramedullary spinal cord ependymomas. Neurosurgery, 1996;39:135-140.

20. Bijlsma EK, Voesten AM, Bijleveld EH, et al.. Molecular analysis of genetic changes in ependymomas. Genes Chromos Cancer, 1995;13:272-277.

21. Von Haken MS, White EC, Daneshvar Shyesther L, et al.. Molecular genetic analysis of chromosome arm 17p and chromosome arm 22q DNA sequences in sporadic pediatric ependymomas. Genes Chromos Cancer, 1996;17:37-44. 